


\title{
Avaliação Multicritério integrada aos Sistemas de Informações Geográficas para geraçã̃o de cenário de suscetibilidade a deslizamentos rápidos em vertentes
}

Autor(es): $\quad$ Pinto, Roberto Carlos; Caneparo, Sony Cortese; Passos, Everton

Publicado por: Imprensa da Universidade de Coimbra

URL

persistente: URI:http://hdl.handle.net/10316.2/37057

DOI: $\quad$ DOI:http://dx.doi.org/10.14195/978-989-26-0983-6_4

Accessed : $\quad$ 26-Apr-2023 11:57:27

A navegação consulta e descarregamento dos títulos inseridos nas Bibliotecas Digitais UC Digitalis, UC Pombalina e UC Impactum, pressupõem a aceitação plena e sem reservas dos Termos e Condições de Uso destas Bibliotecas Digitais, disponíveis em https://digitalis.uc.pt/pt-pt/termos.

Conforme exposto nos referidos Termos e Condições de Uso, o descarregamento de títulos de acesso restrito requer uma licença válida de autorização devendo o utilizador aceder ao(s) documento(s) a partir de um endereço de IP da instituição detentora da supramencionada licença.

Ao utilizador é apenas permitido o descarregamento para uso pessoal, pelo que o emprego do(s) título(s) descarregado(s) para outro fim, designadamente comercial, carece de autorização do respetivo autor ou editor da obra.

Na medida em que todas as obras da UC Digitalis se encontram protegidas pelo Código do Direito de Autor e Direitos Conexos e demais legislação aplicável, toda a cópia, parcial ou total, deste documento, nos casos em que é legalmente admitida, deverá conter ou fazer-se acompanhar por este aviso.

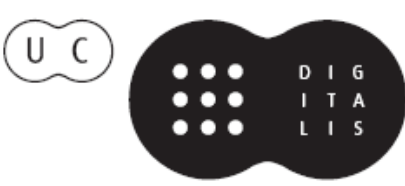




\section{$\forall$ \\ TAS DAS I JORNADAS LUSÓFONAS DE CIÊNCIAS E TECNOLOGIAS DE INFORMAÇÃO GEOGRÁFICA}

Editores

José Gomes dos Santos

Cidália Fonte

Rui Ferreira de Figueiredo

Alberto Cardoso

Gil Gonçalves

José Paulo Almeida

Sara Baptista 


\begin{abstract}
ARTIGO 4
AVAliação MULTiCRITÉrio INTEGRAda AOS Sistemas de INFORMAÇÕES GEOGRÁfICAS PARA GERAÇÃO DE CENÁRIO DE SUSCETIBILIDADE A DESLIZAMENTOS RÁPIDOS EM VERTENTES
\end{abstract}

PINTO, Roberto Carlos ${ }^{1}$; CANEPARO, Sony Cortese ${ }^{2}$ \& PASSOS, Everton 3

\footnotetext{
1 Departamento de Geografia da Universidade Federal do Paraná (Brasil)

Av. Cel. Francisco H dos Santos, 100 - Centro Politécnico - Bloco Setor de Ciências da Terra. Tel: 554133080557; Fax: 554133080557; email: robertogeog@hotmail.com

2 Tel: 554132323995; Fax: 554133613455; email: s_cortese@hotmail.com

3 Tel: 554135730140; Fax: 554133613455; email: everton@ufpr.br
}

\title{
RESUMO
}

Movimentos de massa em vertentes na forma de deslizamentos são importantes processos naturais transformadores do relevo, em áreas habitadas quando desenvolvidos em deslocamentos rápidos tem provocado catástrofes. A identificação e o mapeamento de áreas com suscetibilidade à ocorrência destes processos é importante instrumento auxiliar à gestão e planejamento territorial em áreas de risco. Tais movimentos bruscos de materiais diversos são recorrentes no Brasil, abordados no presente artigo em cenário de suscetibilidade, especificamente quanto a delimitação de áreas em relevo montanhoso, tendo como estudo de caso a Bacia hidrográfica do Rio Jacareí, situada na porção ocidental da Serra da Prata, compreendendo parte dos municípios de Morretes e Paranaguá no Estado do Paraná, afetada fortemente por processos correlatos ocorridos em março de 2011. O estudo descreve a aplicação de uma modelagem preditiva em Sistema de Informações Geográficas por meio da Avaliação Multicritério pelo método da Combinação Linear Ponderada de fatores condicionantes, selecionados, padronizados, posteriormente agregados e combinados. A cartografia do cenário de suscetibilidade resultante foi validada por retroanálise, sobrepondo-se ao 
registro obtido em imagens de cicatrizes do evento reportado, com coincidência aproximada de $82 \%$ em classes mapeadas como Alta e Muito Alta Suscetibilidade, o modelo proposto demonstrou considerável eficiência.

\title{
PALAVRAS-CHAVE
}

Deslizamentos catastróficos, Vertentes, Áreas de suscetibilidade, Processos, Condicionantes.

\author{
MULTICRITERIA EVALUATION FOR INTEGRATED \\ GEOGRAPHIC INFORMATION SYSTEMS \\ FOR GENERATION SCENARIO SUSCEPTIBILITY \\ TO RAPID LANDSLIDES IN SLOPES
}

\begin{abstract}
Mass movements in slopes in the form of landslides are important natural processes of relief transformers, in populated areas when developed in rapid shifts have caused catastrophes. The identification and mapping of areas with susceptibility to these processes is an important instrument to assist management and territorial planning in risk areas. These sudden movements of various materials are recurrent in Brazil, discussed in this paper on susceptibility scenario, specifically regarding the delimitation of areas in mountainous terrain, taking as a case study of the catchment area of the River Jacarei, located in the western portion of the Serra da Prata comprising the municipalities of Morretes and Paranaguá in Paraná State, correlates strongly affected by processes occurring in March 2011. The study describes the application of a predictive modeling in Geographic Information System via Multi-criteria Evaluation method for Weighted Linear Combination of conditioning factors selected, standardized, posteriorly aggregated and combined. The mapping of the resulting susceptibility scenario was validated by back analysis, overlapping the record obtained in images of scars event reported with approximate coincidence of $82 \%$ in classes mapped as High and Very High Susceptibility, the proposed model showed considerable efficiency.
\end{abstract}

\section{KEYWORDS}

Landslides catastrophic, Slope, Areas of susceptibility, Processes, Conditions.

\section{INTRODUÇÃO}

Os diferentes tipos de movimentos com materiais diversos consolidados ou não, constituintes de vertentes, caracterizam-se como importantes processos erosivos responsáveis pela evolução das vertentes e interflúvios 
com consequente assoreamento ou deposição de materiais em fundo de vales ou planícies, afetando o relevo como um todo. Em áreas com predomínio de formas côncavo-convexas em relevo acidentado de serras ou montanhas, é maior a predisposição à ocorrência de movimentos rápidos, em forma de deslizamentos em vertentes, sobretudo em regiões tropicais e subtropicais onde os índices pluviométricos elevados, propiciam grandes variações nas condições hidrodinâmicas.

No Brasil, os "movimentos de massa" em forma de deslizamentos (como são genericamente identificados tais processos) podem alcançar grande magnitude, quando há uma convergência de processos combinando: deslizamentos com desprendimento de blocos; mobilização de detritos, incluindo a cobertura vegetal arbórea, que provoca represamento momentâneo do fluxo fluvial no fundo do vale, com o aporte considerável de água em momentos de elevada precipitação o material inconsolidado argiloso transforma-se em lama, sendo inevitável o rompimento destes represamentos. A persistência pluviométrica origina uma avalanche de lama e detritos incorporando blocos rochosos e materiais deslocados ou desprendidos pelo próprio movimento à jusante. Esta combinação de fenômenos são classificados como movimentos rápidos complexos, e são relativamente frequentes em regiões de serra sendo localmente conhecidos como "cabeça d'água».

São fenômenos preocupantes, pois em território brasileiro há inúmeras áreas urbanas, inseridas em tais condições ambientais, áreas consideradas no contexto de "segurança ambiental" por Bigarella (1974) citando os casos: da Serra das Araras em janeiro de 1967, com 1700 mortes, no Estado do Rio de Janeiro; o de Caraguatatuba São Paulo, com 400 vítimas fatais, ocorrido em março do mesmo ano e Tubarão no Estado de Santa Catarina em março de 1974 com 199 mortes.

Além do elevado número de vítimas os referidos movimentos, acarretam em consideráveis prejuízos socioeconômicos, a exemplo do registrado na região serrana do Estado do Rio de Janeiro em janeiro de 2011, onde segundo Dourado et al. (2012), ocorreram "947 mortes e registrados 300 desaparecidos afetando diretamente uma população de aproximadamente 50.000 pessoas desabrigadas nos municípios de Nova Friburgo, 
Teresópolis, Petrópolis, Sumidouro, São José do Vale do Rio Preto, Bom Jardim e Areal e afetando indiretamente mais de 1.000 .000 de pessoas, sendo investidos $R \$ 188.451 .196,08$ em 79 obras recuperadas pelo poder publico estadual e prejuízos inestimáveis à população”.

Reconhecendo que a ocorrência dos movimentos de "massa generalizados" em vertentes está relacionada ao comportamento de uma série de fatores condicionantes e entendendo que o mapeamento de suscetibilidade é uma etapa importante para a gestão de riscos naturais, este estudo ao propor um modelo de mapeamento preditivo de áreas de suscetibilidade, pode contribuir e em particular servir de instrumento de apoio a medidas preventivas a serem assumidas em órgãos gestores, responsáveis por políticas públicas de planejamento territorial, que visam empregar medidas preventivas, mitigadoras aos impactos negativos causados por desastres associados a estes processos.

Neste contexto, esta pesquisa sugere a utilização da avaliação multicritério (Multi Criteria Evaluation - MCE) integrada aos Sistemas de Informações Geográficas (SIG's) para geração de um cenário de suscetibilidade, a partir da combinação de condicionantes relacionados ao desenvolvimento dos processos de instabilidade em vertentes, utilizando-se do método da Combinação Linear Ponderada (Weighted Linear Combination - WLC) tendo como área modelo uma bacia hidrográfica. A análise classifica-se como estatística, pois apresenta critérios de combinação com padrões mensurados e parte do princípio da existência de relações entre os fatores condicionantes e a distribuição espacial dos movimentos considerados.

\section{APRESENTAÇÃo DO TEMA}

A proposta refere-se à identificação e delimitação das áreas mais propensas ao desprendimento de materiais, que na combinação de fatores que condicionam processos de movimentos rápidos de materiais na vertente, em particular aqueles desencadeados em eventos com elevadas concentrações pluviométricas, em períodos relativamente curtos (poucos dias ou mesmo horas) e tem como objetivo principal a apresentação de um cenário probabilístico, partindo do pressuposto de que a correlação 
entre os condicionantes de instabilidade das vertentes explica a distribuição destes processos no espaço.

Considerou-se ainda que os Sistemas de Informações Geográficas possibilitam, através de avaliação multicritério gerar cenários de suscetibilidade com razoável confiabilidade. Suscetibilidade conforme conceito de Zêzere $(2005,81)$ "probabilidade espacial de ocorrência de um determinado fenômeno numa dada área com base nos fatores condicionantes do terreno, independentemente do seu período de recorrência”.

A avaliação multicritério em ambiente SIG permite a agregação de inúmeras variáveis sendo recomendada para decisões complexas. Zambom et al. (2005, 183) afirmam que “a integração de SIG's e de métodos de decisão multicritério vêm proporcionando inúmeros benefícios para análise de problemas e tomada de decisão no planejamento. Os modelos baseados em decisão multicritério são indicados para problemas onde existam vários critérios de avaliação”.

No caso específico da suscetibilidade aos movimentos, os critérios de valoração são aqueles que aumentam ou diminuem a predisposição de uma determinada área para ocorrência dos processos. "Os critérios selecionados foram combinados e agregados, pelo método da Combinação Linear Ponderada (WLC) que permite a completa compensação entre as variáveis envolvidas" (EASTMAN, 1998).

A área de estudo localiza-se em relevo de serra, no litoral do Estado do Paraná. A Bacia Hidrográfica do Rio Jacareí foi escolhida em função da natureza de deslizamentos ocorridos no mês de março de 2011, caracterizados pela elevada magnitude e poder destrutivo. Na ocasião, um conjunto simultâneo de processos combinados definidos de movimentos complexos envolveram: queda ou desprendimento e rolamento de blocos, escorregamentos de terra, corridas de lama e detritos, que associados a inundações causaram grandes prejuízos socioeconômicos para a comunidade local, destruindo parte da vegetação natural, casas, ruas, pontes, lavouras com uma vítima fatal. (Figuras 1, 2, 3 e 4). 


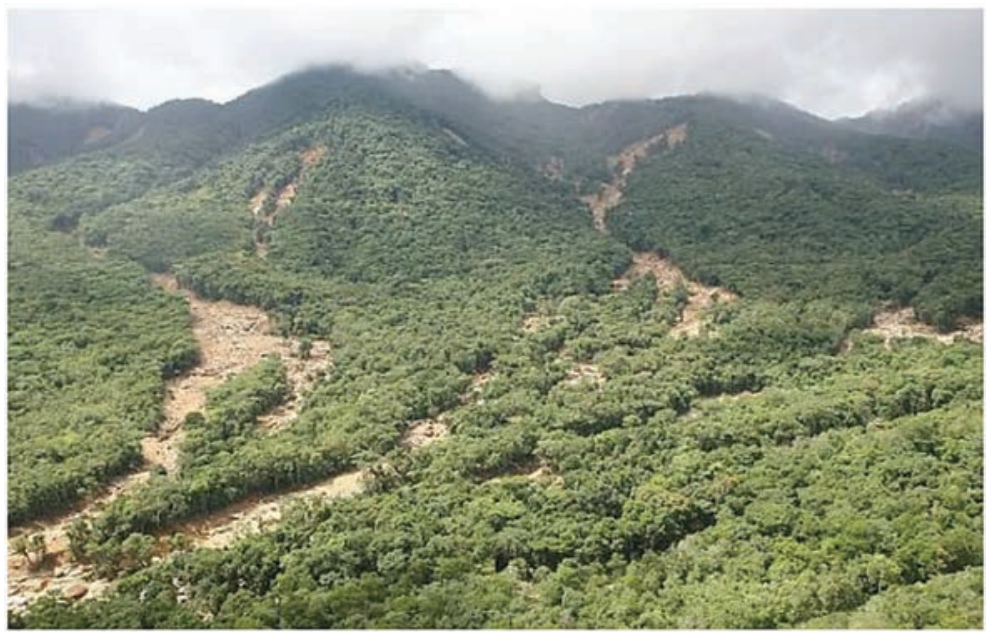

Vista aếrea da encosta do litoral (Foto: Aniele Nascimento / Agência de Noticias Gazeta do Povo)

Figura 1 - Aspectos das cicatrizes erosionais e deposicionais decorrentes de movimentos complexos rápidos em vertentes da Serra da Prata e fundos de vales afetados em 11 de março de 2011. Deslizamentos em forma de escorregamentos e corrida de lama com transporte de detritos incluindo a movimentação de matacões, alguns com dezenas de metros cúbicos, vertente e vale abaixo, provocando o transbordamento e assoreamento do canal fluvial. Fonte: Hedeson S. Jornal Gazeta do Povo, 13/03/2011

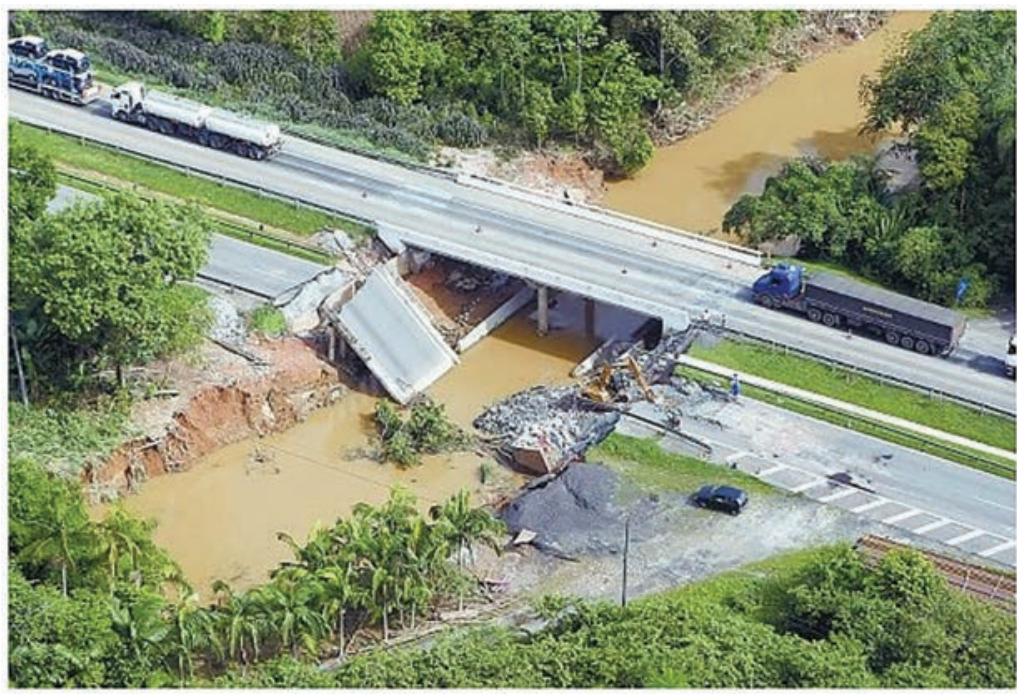

Figura 2 - Destruição pela passagem de detritos decorrentes do evento de movimentos complexos ocorrido a montante. Uma das pontes sobre o Rio Jacareí na rodovia BR 277, principal via de acesso ao porto de Paranaguá, corredor de exportação internacional que atende no Brasil o Estado do Paraná e parte da Região Sul e Região do Pantanal mato-grossense além do Paraguai.

Fonte: Hedeson S. Jornal Gazeta do Povo, 13/03/2011 




Figura 3 - Casa parcialmente destruída pelos movimentos complexos desencadeados nas vertentes da Serra da Prata de 2011

Fonte: Elaboração própria (2012)

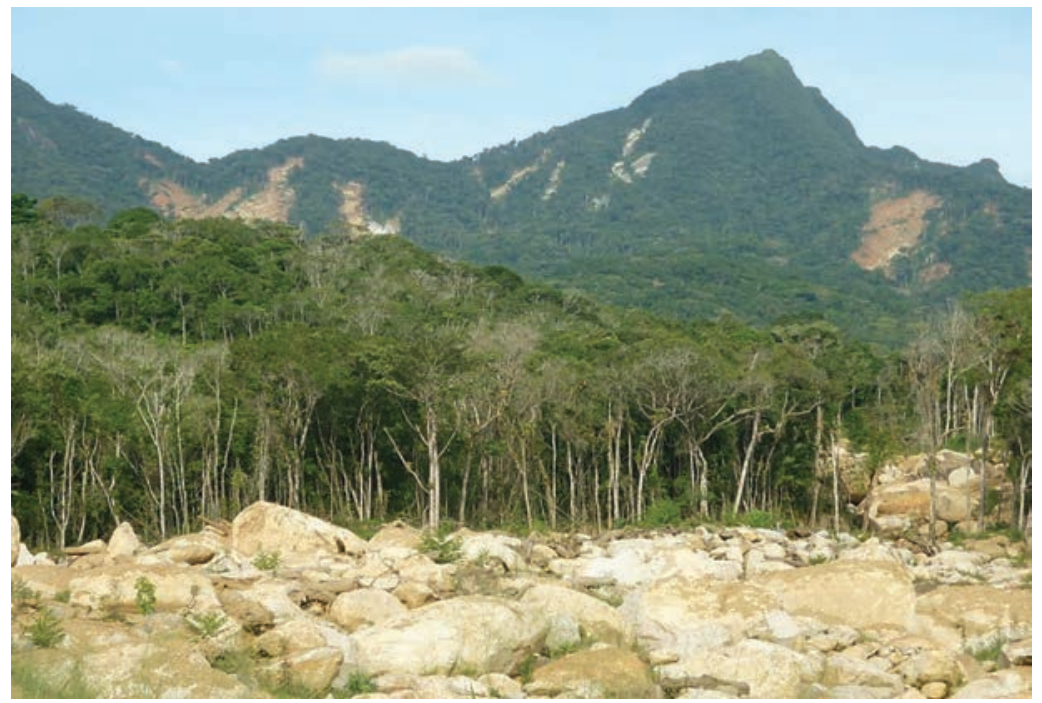

Figura 4 - Matacões de grandes dimensões (eixo maior com aproximadamente de 3 a $7 \mathrm{~m}$ ) deslocados até o fundo de vale destruindo a floresta composta por árvores com o porte das remanescentes (aproximadamente 20 metros de altura) do episódio de 2011, ao fundo algumas cicatrizes dos processos (área fonte de parte do material sedimentado).

Fonte: Elaboração própria (2012) 
A Bacia Hidrográfica do Rio Jacareí localiza-se na divisa dos municípios de Morretes e Paranaguá, Estado do Paraná - Brasil, inserida no compartimento de relevo denominado Serra da Prata (ramificação do grande maciço da Serra do Mar) e na Planície Litorânea, entre as coor-

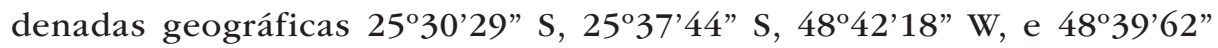
W, com área total de $41,28 \mathrm{~km}^{2}$. (Figura 5 ).

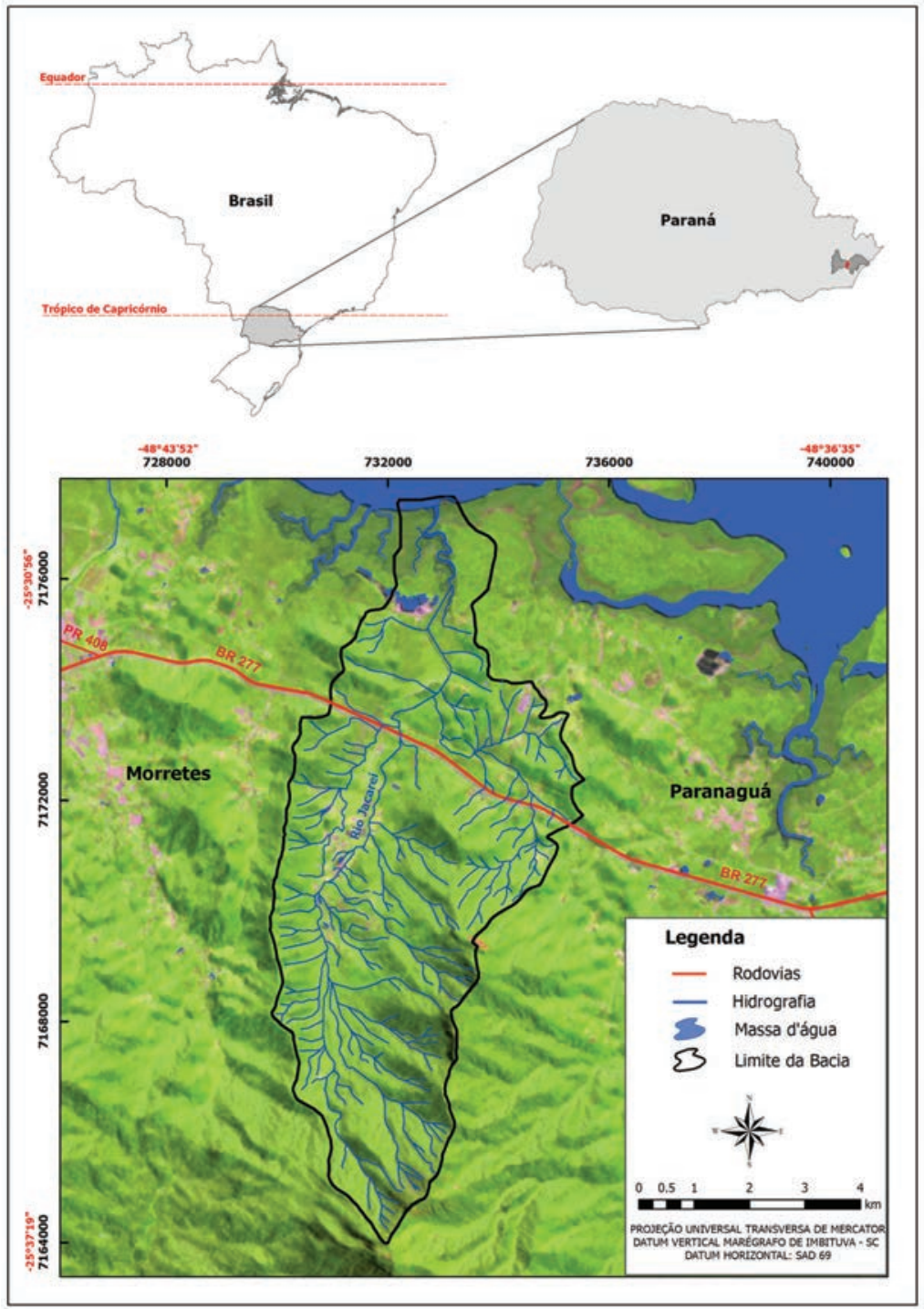

Figura 5 - Cartograma com a localização da Bacia Hidrográfica do Rio Jacareí, divisa entre os municípios de Morretes e Paranaguá - Pr

Fonte: Elaboração própria (2014) 


\section{METODOLOGIA}

Para operacionalização do trabalho foi utilizada a proposta metodológica de Libault (1971), intitulada: Os Quatro Níveis de Pesquisa Geográfica, fundamentada no tratamento quantitativo da informação, com aplicação em dados numéricos, passíveis de representação cartográfica, por meio de mapas-síntese, que representam visualmente o produto da pesquisa. Os níveis da pesquisa definidos pelo autor são os seguintes: compilatório, primeira fase da pesquisa, em que se dá o levantamento dos dados, bem como a compilação destes; correlatório, momento de correlação dos dados e aprimoramento das informações; semântico, com interpretação e análise dos resultados obtidos e normativo, etapa final do trabalho, na qual o produto da pesquisa é transformado em modelo.

Em conjunto com a proposta elaborada por Libault (idem), a agregação e combinação dos fatores condicionantes para geração do cenário de suscetibilidade foi efetuado a partir do método de Avaliação Multicritério denominado: Combinação Linear Ponderada (WLC). Todo o procedimento utilizou-se dos Sistemas de Informações Geográficas IDRISI TAIGA como suporte de operação.

Para desenvolver um modelo de suscetibilidade aos movimentos de vertente é necessário o reconhecimento e análise de uma série de condicionantes de instabilidade, configurando-se em uma avaliação multicritério, técnica que parte da combinação entre vários fatores intrínsecos, pré-definidos criteriosamente, que funcionam como atributos mutuamente correlacionados, em que todos influenciam individualmente e em conjunto no resultado final.

De acordo com Delgado e Barredo Cano (2005, 43) "a avaliação multicritério define-se como um conjunto de técnicas orientadas que contribuem nos processos de tomada de decisão, investigando um grande número de alternativas para múltiplos critérios e objetivos, gerando soluções para problemas diversos”. (Tradução livre do autor).

Entre os métodos de avaliação multicritério, a Combinação Linear Ponderada (WLC) permite, após a padronização e ponderação das variáveis, a compensação entre todos os fatores, conforme peso ou grau 
de importância. Os critérios são agregados e combinados num processo de ponderação entre os mesmos. Os pesos (ou valoração) assumidos governam a compensação. De acordo com Eastman (1998, 188) "o grau com que um fator pode compensar outro, entretanto, é determinado pelo peso". Nesse sentido, um alto escore de potencial de determinado layer em uma determinada área pode compensar um baixo potencial em outro layer nessa mesma área.

\subsection{Determinação dos condicionantes}

Em consulta específica a pesquisas realizadas nos últimos anos, constatou-se que os respectivos autores, geralmente utilizam como fatores condicionantes de instabilidade das encostas e, portanto, de influência direta, na predisposição dos terrenos aos processos de deslizamentos: a declividade, altitude, forma e orientação das vertentes, a litologia, os tipos de solo, a cobertura vegetal e o uso da terra.

Trabalhos como de Ross (1994); Francisco (1996); Crepani et al. (2001); Marcelino (2004); Zaidan (2006); Zêzere et al. (2005); Vanacôr (2006); Silva (2008); Chauhan et al. (2010); entre outros, em que propuseram gerar e analisar modelos de suscetibilidade, perigo, vulnerabilidade, fragilidade e risco associados utilizando-se dos Sistemas de Informações Geográficas, contribuíram para a escolha e padronização dos condicionantes, uma vez que além da adoção dos fatores foram definidos parâmetros de instabilidade para diferentes categorias, validadas em cada estudo específico. Neste contexto foram escolhidos os seguintes condicionantes: declividade, forma das vertentes, altitude, litologia, tipos de solo, uso da terra e cobertura vegetal.

\subsection{Geração dos Planos de Informação (PI's)}

Utilizando-se de produtos cartográficos, informações quantitativas e qualitativas, tais como: dados temáticos (geologia, pedologia, geomorfologia, drenagem, uso da terra, etc.), imagens de satélites e fotos aéreas foram gerados Planos de Informação (PI's) em formato matricial ou raster e vetorial, que formaram um banco de dados de entrada, consolidando a base para o processamento cruzado e geração do modelo. 
Com uso de módulos de modelagem do Software IDRISI TAIGA, desenvolvido pela CLARK LABS (2009), foram gerados e/ou adaptados os seguintes Planos de Informação (PI's) de entrada: declividade; hipsometria; forma das vertentes; litologia; tipos de solo, uso da terra e cobertura vegetal.

\subsection{Padronização dos critérios}

Antes da aplicação do método de avaliação multicritério WLC, como os dados dos fatores encontravam-se em unidades de medida distintas foi necessária à padronização. Nesta etapa foi utilizada a padronização Fuzzy. Souza et al. $(2005,142)$ afirmam que "a finalidade da padronização Fuzzy é colocar todos os fatores considerados na análise, em uma mesma escala, para tornar possível a integração de todos os dados em ambiente de SIG". Conforme Weber e Hasenack $(2001,7)$ "a padronização pode ser feita para um intervalo em nível de byte, entre 0 e 255, utilizando-se funções Fuzzy de pertinência a conjuntos específicos de cada variável, de acordo com critérios estabelecidos".

Neste estudo, a técnica Fuzzy foi ajustada na valoração em relação aos objetivos da pesquisa (em bytes), de modo que 0 indica áreas menos suscetíveis e 255 mais suscetíveis, admitindo valores intermédios. Cada fator condicionante foi reescalonado de acordo com uma ordem de importância, por meio das funções de pertinência Fuzzy (Linear, Sigmoidal, J-shaped e User-Defined). Entretanto, nem todos foram submetidos ao mesmo processo de padronização, por estarem em escala qualitativa ou nominal, nesse caso, foram atribuídos valores diretos entre 0 e 255, conforme potencial considerado.

"Os critérios são de dois tipos: restritivos, que limitam absolutamente as alternativas em análise e fatores, que aumentam ou diminuem a potencialidade de uma alternativa específica" (EASTMAN, 1998). Neste estudo, todos os critérios envolvidos foram considerados fatores e o procedimento de padronização dos mesmos está detalhado nos subitens a seguir: 


\subsubsection{Fator: declividade}

Para a padronização do fator declividade utilizou-se de parâmetros estabelecidos nos trabalhos de Zaidan (2006); Marcelino (2004); Vanacôr (2006). Adotou-se a função sigmoidal crescente, com pontos de controle $\mathrm{a}=25 \mathrm{e} \mathrm{b}=45 \%$ considerou-se que em declividades com ângulos entre 0 e $25 \%$, a encosta é relativamente estável e após este ponto, a suscetibilidade aos movimentos de vertente torna-se maior, estabilizando-se com potencial elevado nos $45 \%$ ou mais. (Figura 6).

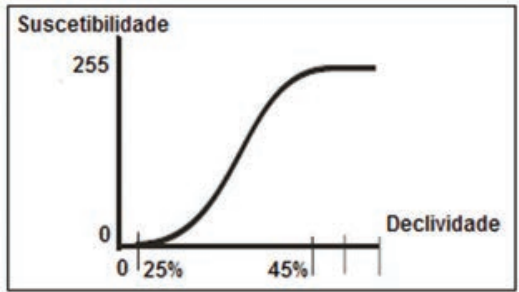

Figura 6 - Sigmoidal Crescente - Declividade Fonte: Adaptado de Eastman (1998)

\subsubsection{Fator: altitude}

De acordo com Crepani et al. (2001, p. 74) "quanto maior a amplitude altimétrica maior é a energia potencial e maior capacidade de morfogênese”. Utilizou-se parâmetros estabelecidos por Francisco (1996) e Marcelino (2004) sendo utilizada a função sigmoidal crescente, com pontos de controle $\mathrm{a}=200$ e $\mathrm{b}=500$ metros de altitude, entendendo que entre 0 e 200 metros, a encosta é relativamente estável com aumento de instabilidade até os 500 metros, estabilizando-se com potencial elevado em altitudes maiores. (Figura 7).

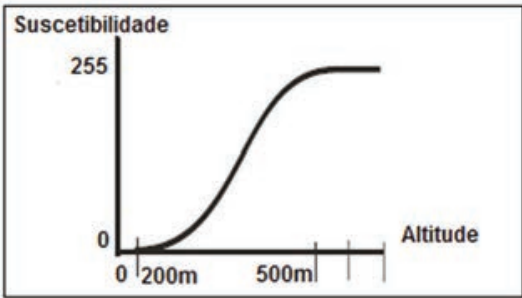

Figura 7 - Sigmoidal Crescente - Altitude Fonte: Adaptado de Eastman (1998) 


\subsubsection{Fator: forma das vertentes}

Para a padronização deste fator, utilizou-se o plano de informação com a curvatura numérica, com variação entre -0.18 a 0.34 . Conforme Valeriano $(2008,36)$ "os valores negativos indicam os perfis côncavos (maior suscetibilidade), positivos os convexos (menor suscetibilidade) e os nulos ou próximos a zero indicam as vertentes retilíneas". Partindo desse pressuposto, adotou-se a função sigmoidal decrescente, com pontos de controle em $\mathrm{c}=-0.18$ e $\mathrm{d}=0.34$, ou seja, à medida que os valores de curvatura aumentam a instabilidade diminui. (Figura 8).

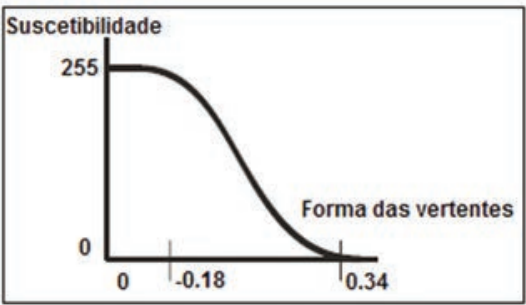

Figura 8 - Sigmoidal Decrescente - Forma das vertentes

Fonte: Adaptado de Eastman (1998)

\subsubsection{Fator: tipos de solo}

Por ser um condicionante com classes nominais foram atribuídos valores entre 0 e 255, para cada classe, baseando-se nos preceitos de Bigarella et al. (2003) ao afirmar que "os solos argilosos são mais suscetíveis, pois estes apresentam descontinuidades dentro do próprio perfil, possuindo horizonte inferior com maior capacidade de armazenamento de água, que resulta em maior facilidade de saturação e consequentemente de movimentação da camada superficial”. (Tabela 1).

\subsubsection{Fator: litologia}

Conforme Crepani et al. (2001) "rochas pouco coesas podem prevalecer os processos erosivos, modificadores das formas de relevo (morfogênese), enquanto que nas rochas bastante coesas devem prevalecer os processos 
de intemperismo e formação de solos (pedogênese)". Baseando-se nesta proposta foram atribuídos valores entre 0 e 255 para cada classe litológica conforme o grau de suscetibilidade aos processos. (Tabela 2).

Tabela 1 - Valores atribuídos de acordo com a suscetibilidade dos solos à erosão e movimentos de vertente

\begin{tabular}{|c|c|}
\hline Classes de solos & Valoração (0 e 255) \\
\hline 1- Gleissolos & 50 \\
\hline 2- Latossolos e Argissolos & 200 \\
\hline $\begin{array}{c}\text { 3 - Cambissolos } \\
\text { e Argissolos }\end{array}$ & 255 \\
\hline $\begin{array}{c}\text { - Cambissolos } \\
\text { e Neossolos }\end{array}$ & 150 \\
\hline 5 - Neossolos Litólicos & 100 \\
\hline $\begin{array}{c}\text { 6- Neossolos e } \\
\text { Afloramentos }\end{array}$ & 100 \\
\hline 7 - Afloramentos Rochosos & 50 \\
\hline
\end{tabular}

Fonte: Elaboração própria (2014).

\subsubsection{Fator: uso da terra e cobertura vegetal}

Também com classes nominais, este condicionante foi padronizado numa escala de valores entre 0 e 255, com parâmetros definidos com base nas propostas de Ross (1994) e Crepani et al. (2001). (Tabela 3).

\subsection{Ponderação das variáveis}

Considerando que os condicionantes de instabilidade das vertentes interferem com pesos diferenciados de influência, após a padronização Fuzzy foi necessário recorrer à ponderação das variáveis. Utilizou-se para este procedimento, a proposta de Saaty (1980), técnica AHP (Analytical Hierarchy Process), passível de ser efetuado no módulo WEIGHT do Software IDRISI. "Esse método de comparação da importância relativa das variáveis, duas a duas, auxilia no estabelecimento dos pesos finais dos fatores diminuindo a subjetividade" (WEBER \& HASENACK, 2001, 7). 
Tabela 2 - Valoração do grau de resistência das rochas para o intemperismo e erosão

\begin{tabular}{|c|c|c|c|}
\hline $\begin{array}{l}\text { Unidade } \\
\text { Geológica }\end{array}$ & Sigla & Classes litológicas & $\begin{array}{l}\text { Valores } \\
(0-255)\end{array}$ \\
\hline \multirow{3}{*}{$\begin{array}{l}\text { Complexo } \\
\text { Gnáissico- } \\
\text { Migmatítico }\end{array}$} & APImge & $\begin{array}{l}\text { Migmatitos estromáticos com paleosoma de } \\
\text { biotita-hornblenda gnaisse, mica-quartzo } \\
\text { xisto, ultrabasito, metabasito e anfibolito }\end{array}$ & 100 \\
\hline & APImgm & $\begin{array}{l}\text { Migmatitos oftálmicos, com paleosoma de } \\
\text { biotita gnaisse, biotita-hornblenda gnaisse e } \\
\text { hornblenda gnaisse, localmente com quartzitos }\end{array}$ & 100 \\
\hline & APIsgf & $\begin{array}{l}\text { Suíte granítica foliada, granitos metasso- } \\
\text { máticos ou de anatexia, indiferenciados }\end{array}$ & 100 \\
\hline $\begin{array}{l}\text { Complexo } \\
\text { Metamórfico } \\
\text { Indiferenciado }\end{array}$ & APIrmx & $\begin{array}{l}\text { Biotita-muscovita xistos e clorita-bio- } \\
\text { tita-muscovita xistos, com ocorrências } \\
\text { locais de quartzo xistos e quartzitos }\end{array}$ & 150 \\
\hline \multirow{6}{*}{$\begin{array}{l}\text { Sedimentos } \\
\text { Recentes }\end{array}$} & Qha2 & Aluviões recentes & 200 \\
\hline & Qhc & $\begin{array}{l}\text { Depósito de colúvio associados à depósitos } \\
\text { de tálus, com argila, silte, areias e seixos }\end{array}$ & 255 \\
\hline & Qhes & Cascalheiras continentais retrabalhadas & 255 \\
\hline & QHmg & $\begin{array}{l}\text { Sedimentos fluviomarinhos, as- } \\
\text { sociados à manguezais }\end{array}$ & 150 \\
\hline & QHmo & $\begin{array}{l}\text { Sedimentos argilo-síltico-are- } \\
\text { nosos, paleoestuarinos }\end{array}$ & 255 \\
\hline & Qt & Depósitos de tálus, blocos em matriz argilosa & 255 \\
\hline $\begin{array}{l}\text { Formação } \\
\text { Alexandra }\end{array}$ & $\mathrm{Ta}$ & Conglomerados, arcósios, areias e argilitos & 200 \\
\hline
\end{tabular}

Fonte: Elaboração própria (2014)

Tabela 3 - Valores atribuídos à suscetibilidade de acordo com uso da terra e cobertura vegetal

\begin{tabular}{|c|c|}
\hline Uso e ocupação da terra e cobertura vegetal & Valoração (0 e 255) \\
\hline 1 Agricultura anual & 150 \\
\hline 2 Agricultura perene & 150 \\
\hline 3 Área construída & 255 \\
\hline 4 Campos de altitude & 100 \\
\hline 5 Corpos d'água & 150 \\
\hline 6 Floresta estágio inicial & 100 \\
\hline 7 Floresta estágio médio ou avançado & 50 \\
\hline 8 Mangues & 0 \\
\hline 9 Ocupação rural & 150 \\
\hline 10 Pastagens e campos & 150 \\
\hline 11 Reflorestamento & 100 \\
\hline 12 Solo exposto ou mineração & 255 \\
\hline
\end{tabular}

Fonte: Elaboração própria (2014) 
Nos quadros I e II são apresentadas as escalas pré-definidas de valores a serem atribuídos por meio da técnica AHP, proposta por Saaty (op. cit.).

Quadro I - Escala de valores AHP para comparação pareada

Intensidade de importância

1

9

$2,4,6,8$
Definição e Explicação

Importância igual - os dois fatores contribuem igualmente para o objeto

Importância moderada - um fator é ligeiramente mais importante que o outro Importância essencial - um fator é claramente mais importante que o outro Importância demonstrada - um fator é fortemente favorecido e sua maior relevância foi demonstrada na prática Importância extrema - a evidência que diferencia os fatores é da maior ordem possível

Valores intermediários entre julgamentos - possibilidade de compromissos adicionais

Fonte: Adaptado de Saaty (1980).

Quadro II - Escala de comparação de critérios

$\begin{array}{ccccccccc}1 / 9 & 1 / 7 & 1 / 5 & 1 / 3 & 1 & 3 & 5 & 7 & 9 \\ \begin{array}{c}\text { extrema- } \\ \text { mente }\end{array} & \begin{array}{c}\text { bas- } \\ \text { tante }\end{array} & \begin{array}{c}\text { mui- } \\ \text { to }\end{array} & \begin{array}{c}\text { pou- } \\ \text { co }\end{array} & \text { igual } & \text { pouco } & \begin{array}{c}\text { mui- } \\ \text { to }\end{array} & \begin{array}{c}\text { bas- } \\ \text { tante }\end{array} & \begin{array}{c}\text { extrema- } \\ \text { mente }\end{array}\end{array}$

MENOS

IMPORTANTE
MAIS

IMPORTANTE

Fonte: Adaptado de Saaty (1980)

A técnica AHP combina os diversos critérios atribuindo-lhes pesos e ponderando a participação individual no processo, resultando em pesos finais de importância relativa para cada critério. "Uma das vantagens desse processo é a possibilidade de refazer o cálculo dos pesos quantas vezes julgar-se necessário, pois o método informa os novos pesos juntamente com uma razão de consistência (CR- Consistency Ratio) alertando o usuário sobre possíveis equívocos.” (EASTMAN, 1998, 187).

Os fatores foram organizados na matriz de comparação pareada, técnica AHP, resultando em pesos finais de influência e na razão de consistência. (Tabela 4, Quadro III). 
Tabela 4 - Determinação dos pesos de importância relativa para suscetibilidades

\begin{tabular}{|c|c|c|c|c|c|c|}
\hline & Altitude & $\begin{array}{c}\text { Uso e } \\
\text { cobertura } \\
\text { Vegetal }\end{array}$ & Litologia & $\begin{array}{c}\text { Forma Das } \\
\text { Vertentes }\end{array}$ & $\begin{array}{c}\text { Tipos de } \\
\text { Solo }\end{array}$ & Declividade \\
\hline Altitude & 1 & 1 & 1 & & & \\
\hline $\begin{array}{c}\text { Uso e } \\
\text { cobertura } \\
\text { Vegetal }\end{array}$ & 2 & 2 & 2 & 1 & & \\
\hline $\begin{array}{c}\text { Litologia } \\
\begin{array}{c}\text { Forma } \\
\text { das } \\
\text { Vertentes }\end{array}\end{array}$ & 3 & 2 & 2 & 1 & & \\
\hline $\begin{array}{c}\text { Tipos } \\
\text { de Solo }\end{array}$ & 5 & 3 & 4 & 3 & & 1 \\
\hline $\begin{array}{c}\text { Declivi- } \\
\text { dade }\end{array}$ & 7 & 5 & & & & \\
\hline
\end{tabular}

Fonte: Elaboração própria (2014)

Quadro III - Pesos calculados - Suscetibilidade

\section{FATORES}

Altitude Fuzzy
Uso do solo e cobertura vegetal Fuzzy
Litologia Fuzzy
Forma das vertentes Fuzzy
Tipos de Solo Fuzzy
Declividade Fuzzy

Altitude Fuzzy

Litologia Fuzzy

Tipos de Solo Fuzzy

Fonte: Software IDRISI TAIGA. Atividade de laboratório

Razão de Consistência $=0.01$ (Consistência é aceitável)

\section{PESOS FINAIS}
0.0447
0.0740
0.1116
0.1658
0.2036
0.4003

\subsection{Método da Combinação Linear Ponderada - WCL}

De posse dos fatores devidamente padronizados pela técnica Fuzzy, com valoração contínua entre 0 a 255 (bytes) e com seus pesos finais de importância relativa, resultantes da ponderação pela técnica AHP foi possível efetuar o processo de agregação entre todos os fatores condicionantes envolvidos, estes foram submetidos ao método de compensação, pela Combinação Linear Ponderada (Weighted Linear Combination - WCL) presente no módulo de avaliação por critérios múltiplos (Multi Criteria Evaluation - MCE), do software IDRISI.

No método WLC, os pesos dos fatores usados expressam a importância relativa de cada critério e determinam como os fatores são compensados 
entre si. Portanto, um fator como a cobertura vegetal formada por floresta em estágio médio ou avançado pode atenuar potenciais mais elevados de suscetibilidade gerados, por exemplo, pela declividade acentuada. "O programa multiplica cada fator por seu peso correspondente somando a seguir o resultado". (EASTMAN, 1998).

\section{APRESENTAÇÃo DOS DADOS}

\subsection{Cenário de Suscetibilidade}

No mapa resultante da WLC (Figura 9), observa-se a variação dos níveis de suscetibilidade em que cada pixel representa o valor recebido em todo o processo que considerou os critérios condicionantes adotados e padronizados, com seus respectivos pesos de importância relativa. Os pixels com maiores valores, representados com cores avermelhadas, indicam as áreas que apresentam maior suscetibilidade aos movimentos de vertente, com as zonas de origem dos processos e os pixels com valores tendendo a 0 representam os locais de menor suscetibilidade.

Como a Combinação Linear Ponderada faz a total compensação entre os fatores utilizados, os escores de suscetibilidade da área, se apresentaram relativamente baixos. O nível máximo de suscetibilidade obteve um escore de 229, na escala de variação entre 0 a 255. Sendo assim, no processo de agregação e combinação ficou evidenciada a compensação entre classes de fatores com valoração indicando mais propensão às ocorrências dos movimentos de vertente com categorias que favorecem a estabilidade da mesma.

O mapa demostrou razoável consistência, uma vez que os pixels com coloração representando maiores níveis de suscetibilidade se concentraram principalmente nas maiores altitudes, elevadas declividades da Serra da Prata (margem direita do Rio Jacareí), em terrenos formados por solos rasos e afloramentos rochosos indicando o predomínio da morfogênese em detrimento da pedogênese. Por outro lado, os pixels com coloração demonstrando menor suscetibilidade concentraram na área de planície de inundação, com baixas declividades e solos mais espessos com predomínio da pedogênese. 

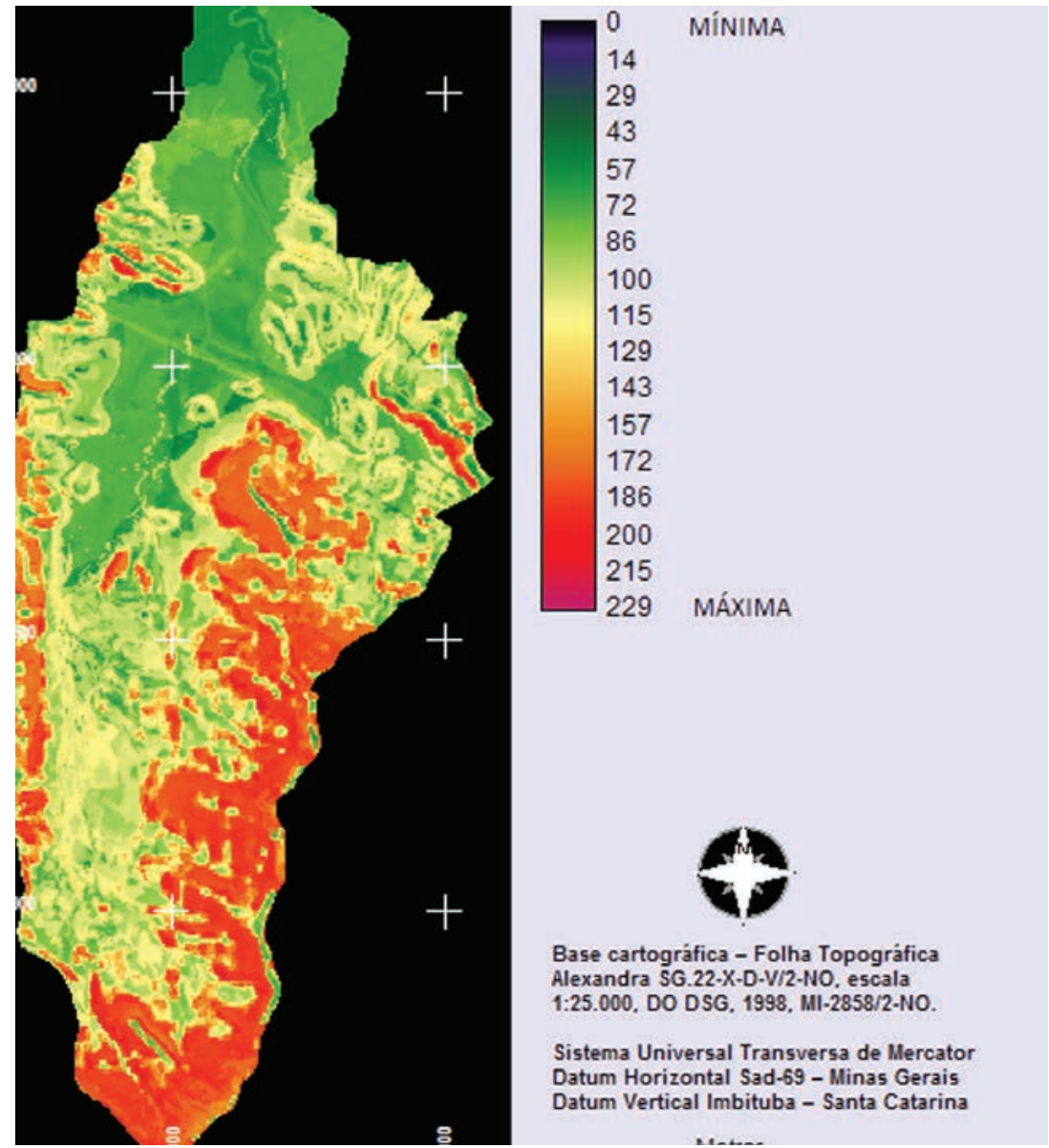

Figura 9 - Mapa de suscetibilidade resultante do método de Combinação Linear Ponderada - WLC

Fonte: Elaboração própria (2014)

A partir da grade numérica, representando uma visão contínua da variação da grandeza suscetibilidade a movimentos de vertente, foi realizada a reclassificação pelo método do desvio quartílico visando categorizar o modelo em diferentes níveis de suscetibilidade. De acordo com Ramos e Sanchez (2000), "este método divide a série de dados em quatro grupos com igual número de ocorrências, cada um compreendendo $25 \%$ do total de valores. Desta forma, o fatiamento é definido quantitativamente, excluindo a subjetividade no processo de definição do limiar de corte”. 
Seguindo esta proposta, a imagem original foi dividida em quatro intervalos de suscetibilidade: de 0 a 63 (classificada como baixa suscetibilidade), de 63 a 127 (moderada suscetibilidade), de 127 a 191 (alta suscetibilidade) e de 191 a 255 (muito alta suscetibilidade).

O fatiamento em categorias de suscetibilidade foi realizado com uso do módulo RECLASS, do Software IDRISI, resultando no mapa com classes de suscetibilidade aos movimentos de vertente (zonas de origem de desprendimento de materiais) para a área de estudo. (Figura 10).

A análise do mapa síntese (Figura 10) com quatro níveis categóricos de suscetibilidade permitiu inferir que na Bacia Hidrográfica do Rio Jacareí ocorre o predomínio das classes Moderada e Baixa suscetibilidade, localizadas principalmente, no terço médio e na planície de inundação respectivamente. Em termos percentuais as classes descritas representam $68,13 \%$ da área total da bacia, enquanto que as classes de Alta e Muito Alta suscetibilidade representam 31.87\%, conforme pode ser observado na Tabela 5 .

Tabela 5 - Distribuição da área, por graus de suscetibilidade a movimentos de vertente

\begin{tabular}{|c|c|c|}
\hline Classes de Suscetibilidade & Área (ha) & $\%$ \\
\hline Baixa & 1087,66 & 26,35 \\
\hline Moderada & 1727,70 & 41,78 \\
\hline Alta & 795,06 & 19,26 \\
\hline Muito Alta & 520,42 & 12,61 \\
\hline
\end{tabular}

Fonte: Cálculo de área utilizando-se do software IDRISI TAIGA. Atividade de laboratório

Neste modelo, os pesos de cada critério considerados baixos ou elevados tendem a se aproximar de uma média, de modo que, a total compensação (1) tem como característica principal a de gerar modelos homogeneizados, levando a valores medianos. 




\section{WLC - CLASSES DE SUSCETIBILIDADE}

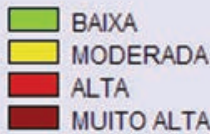

Figura 10 - Mapa síntese com classes de suscetibilidade Fonte: Elaboração própria (2014)

\section{DISCUSSÃo DOS RESULTADOS}

Os resultados apresentados no mapa síntese de áreas com suscetibilidade a movimentos rápidos em vertentes (Figura 10) e observações em campo demonstraram compatibilidade entre o cenário produzido e as condições reais presenciadas. Quanto às características de relevo identificadas como áreas mais instáveis, com as classes Alta e Muito Alta suscetibilidade, estas estão situadas na margem direita do Rio Jacareí, onde as vertentes apresentam declividades elevadas, superiores a $30 \%$ e concentram-se principalmente no terço superior, as altitudes acima dos 
400 metros, sendo que as declividades e os gradientes altimétricos nesses pontos sustentados por rochas mais resistentes ao intemperismo, onde predominam os granitóides. Os solos são rasos e apresentam-se associados a afloramentos rochosos caracterizando o predomínio da morfogênese sobre a pedogênese nestes setores das vertentes. Na margem esquerda do Rio Jacareí as áreas de Muito Alta e Alta suscetibilidade ocorrem com menor intensidade, situam-se também preferencialmente no terço médio das vertentes, em litologia de natureza metamórfica.

Por meio do procedimento de retroanálise, as ocorrências reais de deslizamentos mapeadas, registradas na paisagem em forma de cicatrizes dos movimentos nas vertentes de março de 2011 serviram como base para o cruzamento com os modelos gerados e verificação dos níveis de coincidência entre as classes de suscetibilidade estabelecidas com as zonas de origem dos movimentos.

No mapeamento (Figura 11), com base na imagem de satélite WordView1, resolução espacial de 0,6 metros, datada do dia 05 de maio de 2011, disponibilizada por Silveira et al. (2013), foram registradas de 288 cicatrizes, equivalente a $2,06 \mathrm{~km}^{2}$ ou $5,14 \%$ da área.

Comparando as categorias obtidas pelo método probabilístico multicriterial WLC e o referido mapa de cicatrizes por meio do módulo CROSSTAB (tabulação cruzada) do Software IDRISI, verificou-se que 81,80\% coincidem com as classes identificadas como Alta e Muito Alta Suscetibilidade, $31,86 \%$ e 49,94\% respectivamente, com maior concordância na margem direita do Rio Jacareí onde encontra-se o compartimento geológico com predomínio de rochas graníticas denominado de Serra da Prata, demonstrando considerável consistência do método utilizado, sendo portanto recomendável a estudos preditivos.

Áreas classificadas como de elevada suscetibilidade (Classes Alta e Muito Alta) onde não ocorreram sobreposições e, portanto que não sofreram deslizamentos estão no mesmo contexto físico-natural daquelas em que grandes volumes de materiais vieram encosta abaixo e se enquadram na mesma condição de instabilidade, portanto passíveis de movimentação futura, em recorrência de eventos pluviométricos similares. (Figura 12). 


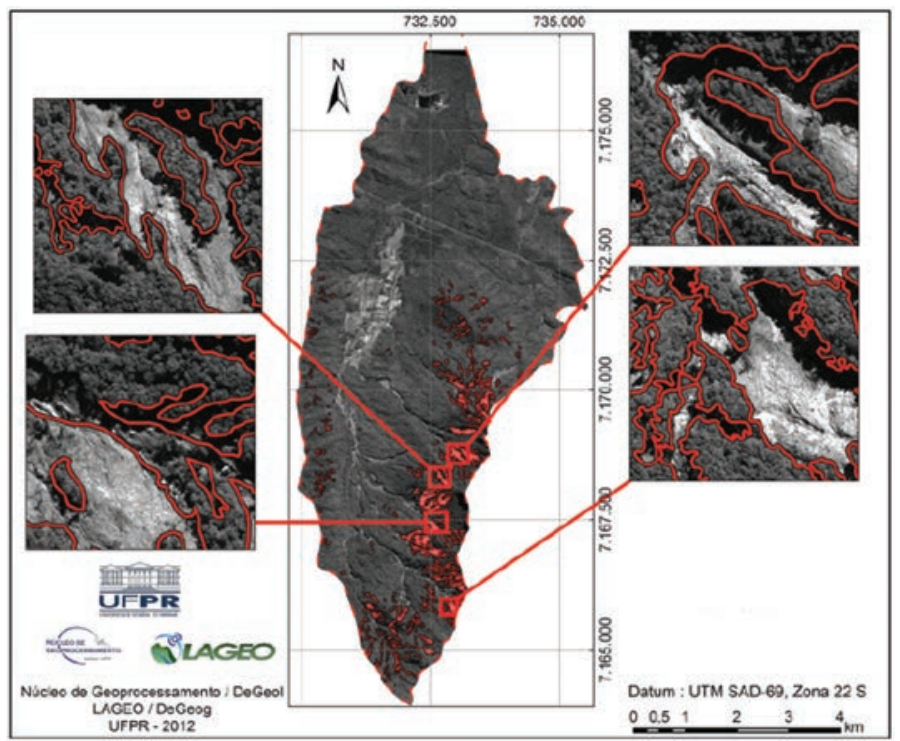

Figura 11 - Delimitação das cicatrizes com zonas de origem dos movimentos de vertente (escorregamentos, queda e rolamento de blocos)

Fonte: Imagem de satélite WordView 1, imageamento em 05 de maio de 2011. Org.: Silveira et al. (2013)

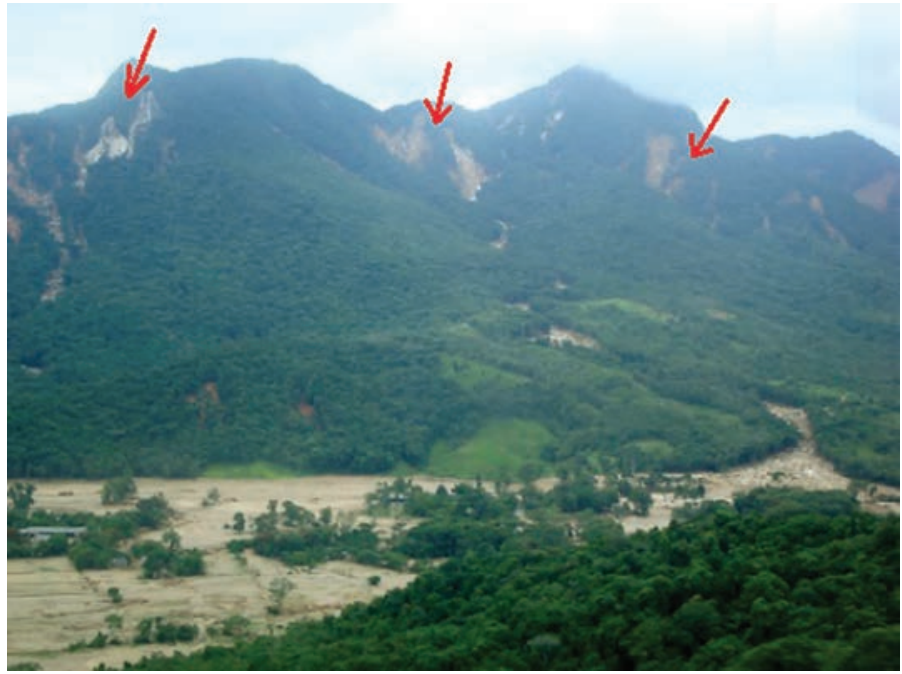

Figura 12 - Foto obtida imediatamente após o evento demonstrando a existência de remanescentes de áreas florestadas apontadas pelos presentes autores com setas em vermelho

onde não houve escorregamento ou desprendimento de blocos, inseridas no mesmo contexto de suscetibilidade das áreas adjacentes marcadas pelas cicatrizes cujo material transportado registrado em primeiro plano na foto o qual foi depositado em forma de cone de dejeção, recobrindo a planície de inundação do Rio Jacareí assoreando o canal fluvial 
É importante ressaltar que o método WLC tem como principal característica a compensação global entre os fatores avaliados, cuja potencialidade e/ou suscetibilidade demonstrada a partir da combinação dos fatores prioriza a importância relativa de cada um e por isso tende a resultar em valores medianos.

Outra questão relevante refere-se às condições de pluviosidade específicas do evento de março de 2011, em que a instabilidade das vertentes se deu principalmente devido os elevados valores pluviométricos. Pois a chuva acumulada, não apenas do dia 11 de março de 2011 totalizada em 230,6 mm, mas também ao fato de que nos dias 10, 11 e 12 daquele mês, os índices somados foram de $382,2 \mathrm{~mm}$, muito acima da normalidade SIMEPAR (2011). Guidicine e Iwasa (1976) afirmam que com "índices de pluviosidade acima de 250-300 mm em 72 horas os movimentos em vertente são generalizados tanto em áreas alteradas pela ocupação humana quanto em áreas virgens".

\section{CONCLUSÃo}

Modelos de suscetibilidade como o tratado neste estudo é uma etapa imprescindível na gestão de riscos de desastres naturais, portanto é muito importante que novas metodologias sejam testadas com objetivo de aprofundar o conhecimento referente à temática, visando diminuir os impactos negativos que os fenômenos tratados eventualmente provocam para a sociedade em geral.

O cenário de suscetibilidade a movimentos rápidos de grandes volumes nas vertentes da Bacia Hidrográfica do Rio Jacareí, gerado por meio da avaliação multicritério, método da Combinação Linear Ponderada, por meio dos Sistemas de Informações Geográficas demonstrou considerável eficiência, uma vez que resultou em aproximadamente $82 \%$ de coincidência de áreas classificadas como de Alta e Muito Alta Suscetibilidade, com o mapeamento das cicatrizes ocorridas no episódio de março de 2011, e que abrangem cerca de $30 \%$ da área total da bacia.

Outra possibilidade de modelagem e análise de suscetibilidade envolvendo metodologia semelhante é a avaliação multicritério pelo método 
da Media Ponderada Ordenada (Ordered Weighted Average - OWA), uma derivação da Combinação Linear Ponderada, que além dos fatores padronizados e ponderados permite a atribuição de um segundo conjunto de pesos, com intuito de controlar a compensação e o risco associado à tomada de decisão. Neste sentido, ensaios futuros poderão ser efetuados na perspectiva de alcançar melhores resultados.

Quanto a subjetividade na atribuição de valores para os condicionantes adotados e respectivas classes, tanto no processo de padronização, como na ponderação de pesos de importância relativa, há de se considerar o uso de um procedimento possível na definição dos parâmetros de instabilidade com base no detalhamento de estudo da tipologia diversificada dos processos envolvidos na movimentação dos materiais, com estudo "in loco" e relação com a diversidade de cicatrizes registradas no inventário existente que ora expõem rocha sã ou com variações no grau de alteração do manto de intemperismo sob diferentes condições litológicas e de relevo.

\section{BIBLIOGRAFIA}

BIGARELLA, Joao José (1974) - Segurança ambiental uma questão de consciência e muitas vezes de segurança nacional. Brasília: Associação dos Diplomados da Escola Superior de Guerra. 66p.

BIGARELLA, Joao José et al. (2003) - Estrutura e origem das paisagens tropicais e subtropicais. Florianópolis: Ed. Da UFSC, 2003 v. 3 (p. 877-1436).

CHAUHAN, Shivani et al. (2010) - Landslide susceptibility zonation through ratings derived from artificial neural network. International Journal of Applied Earth Observation and Geoinformation, v. 12, p. 340-350.

CREPANI, Edison et al. (2001) - Sensoriamento Remoto e Geoprocessamento Aplicados ao Zoneamento Ecológico-Econômico e ao Ordenamento Territorial. São José dos Campos: INPE.

DELGADO Montserrat Gomes; BARREDO CANO José (2005) - Sistemas de Información Geográfica y evaluación multicriterio en la ordenación del territorio ( $2^{\mathrm{a}}$ Ed.) Alfaomega, México.

DOURADO, Francisco et al. (2012) - O Megadesastre da Região Serrana do Rio de Janeiro as Causas do Evento, os Mecanismos dos Movimentos de Massa e a Distribuição Espacial dos Investimentos de Reconstrução no Pós-Desastre. 
Anuário do Instituto de Geociências - UFRJ - Vol. 35 - 2 p.43-54.

EASTMAN, Ronald (1998) - Idrisi for Windows: Introdução e Exercícios Tutoriais - Versão 2. Tradução: Heinrich Hasenack e Eliseu Weber. Porto Alegre: UFRGS - Centro de Recursos Idrisi.

FRANCISCO, Cristiane Nunes (1996) - Mapeamento das áreas de riscos de deslizamentos e desmoronamentos do Parque Nacional da Tijuca (RJ) e entorno através de Sistemas Geográficos de Informação. $1^{a}$ Semana Estadual de Geoprocessamento - Rio de Janeiro- Clube de Engenharia 197-209. Disponível online no endereço url: http://www.professores.uff.br/cristiane/Documentos/ SEGEO_1996b.pdf. (acedido em 03 de julho, 2013).

GUIDICINI, Guido \& IWASA, Oswaldo Yujiro (1976) - Ensaio de correlação entre pluviosidade e escorregamentos em meio tropical úmido. São Paulo: IPT, $48 \mathrm{p}$.

LIBAULT, André (1971) - Os quatro níveis da pesquisa geográfica. Métodos em Questão. (1). São Paulo: IGEO/USP.

MARCELINO, Emerson Vieira (2004) - Mapeamento de áreas suscetíveis a escorregamento no município de Caraguatatuba (SP) usando técnicas de sensoriamento remoto e SIG. São José dos Campos. 228p. Dissertação (Mestrado em Sensoriamento Remoto) - Instituto Nacional de Pesquisas Espaciais, 2004

MINEROPAR (MINERAIS DO PARANÁ S/A) - (2011) Mapeamento Geológico Geotécnico da Porção Leste da Serra do Mar do Estado do Paraná. MINEROPAR (Minérios do Paraná S/A), 91p.

RAMOS, Cristhiane da Silva \& SANCHEZ, Miguel Cezar (2000) - Estudo metodológico de classificação de dados para cartografia temática. Geografia, v. 25 , n. 2, p. 23-52.

ROSS, Jurandyr Luciano Sanches (1994) - Análise Empírica da Fragilidade dos Ambientes Naturais e Antropizados. Revista do Departamento de Geografia, n. 8, São Paulo: FFLCH/USP, 1994.

SAATY, Thomas (1980) - Analytical Hierarchy Process: Planning, Priority Setting, Resource Allocation. MCGraw-Hill, New York, NY, USA.

SIMEPAR - Sistema Meteorológico do Paraná (2011). Alturas pluviométricas do Estado do Paraná (março de 2011). Disponível online no endereço url: http://www.simepar.br/ (acedido em 15 de setembro, 2013).

SILVA, Marcos Antônio (2008) - Aplicação de lógica nebulosa para previsão do risco de escorregamentos de taludes em solo residual. Rio de Janeiro. 150p. Dissertação (Mestrado em Engenharia Civil) - UFRJ. (2008).

SILVEIRA, Claudinei Taborda et al. (2013) - Análise do fator de segurança da estabilidade das vertentes na bacia do Rio Jacareí, Serra do Mar paranaense. Revista Brasileira de Geomorfologia, 13(3). 
SOUZA, Luiz Carlos et al. (2005) - Estudo do Meio Físico na Avaliação de Bacias Hidrográficas Utilizadas como Mananciais de Abastecimento. In: ANDREOLI, C. V.; CARNEIRO, C. Gestão Integrada de Mananciais de Abastecimento Eutrofizados. Curitiba: SANEPAR - Finep. 500 p. 123 - 158.

VALERIANO, Marcio de Morisson (2008) - TOPODATA: Guia de utilização de dados geomorfométricos locais. São José dos Campos: INPE, 2008. 44p.

VANACÔR, Roberto Nunes (2006) - Sensoriamento remoto e geoprocessamento aplicados ao mapeamento das áreas suscetíveis a movimentos de massa na região nordeste do Estado do Rio Grande do Sul. Dissertação (Mestrado). Universidade Federal do Rio Grande do Sul. Disponível online no endereço url: http://hdl.handle.net/10183/8344 (acedido em 07 de março, 2012).

WEBER, Eliseu \& HASENACK, Heinrich (2001) - Avaliação de áreas para a instalação de aterro sanitário através de análises em SIG com classificação contínua dos dados. Universidade Luterana do Brasil, Canoas - RS.

ZAIDAN, Ricardo Tavarez (2006) - Risco de escorregamento numa bacia de drenagem urbana no município de Juiz de Fora - MG. Rio de Janeiro: UFRJ/ PPGG, 2006. 99p. Tese (Doutorado em Geografia).

ZAMBON, Kátia Lívia et al. (2005) - Análise de decisão multicritério na localização de usinas termoelétricas utilizando SIG. Pesquisa Operacional, Rio de Janeiro, v.25, n.2, p.183-199.

ZÊZERE, José Luis (2005) - Dinâmica de vertentes e risco geomorfológico. Centro de Estudos Geográficos, Relatório N.²41, Lisboa.

ZÊZERE, José Luis et al. (2005) - Análise sensitiva na avaliação da susceptibilidade a deslizamentos na região a norte de Lisboa. Centro de Estudos Geográficos, Universidade de Lisboa. Disponível online no endereço url: http://www.rc.unesp.br/igce/planejamento/download/isabel/analise_sensitiva.pdf (acedido em 11 de outubro, 2013). 
Série Documentos

Imprensa da Universidade de Coimbra

Coimbra University Press

2015

- U M

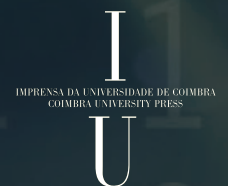

